\title{
A mística do cuidado em Albert Schweitzer
}

\author{
Josias da Costa Júnior*
}

\section{Resumo}

O objetivo deste artigo é discutir alguns aspectos da mística do cuidado a partir do pensamento de Albert Schweitzer. Sua noção de "reverência pela vida" é fundamental para compreensão do seu pensamento e implica profundo respeito a todas as formas de vida (humana e não humana). Essa atitude de respeito é encontrada em sua postulação ética, baseada na experiência mística do desejo de viver, que se manifesta em todos os seres vivos. É, portanto, através da compreensão dessa noção de reverência pela vida que a mística do cuidado encontra sua expressão. O trabalho privilegiará escritos do próprio Albert Schweitzer e de Martin Heidegger para entender a noção de cuidado. Palavras-chave: mística; cuidado; religião

\section{The mystique of care in Albert Schweitzer}

\begin{abstract}
The purpose of this article is to discuss some aspects of the mystique of care from the thought of Albert Schweitzer. His notion of "reverence for life" is crucial to understand his thought and involves deep respect for all forms of life (human and not human).This attitude of respect is found in his ethical postulation, based on the mystical experience of the desire to live, which is manifested in all living beings. It is through understanding the concept of reverence for life that the mystique of care finds its expression. The work will focus on the writings of Albert Schweitzer himself and Martin Heidegger to understand the notion of care.
\end{abstract}

Keywords: mystique; care; religion

* Doutor em Teologia pela PUC-Rio, com Pós-Doutorado no Departamento de Estudos Literários da UFF. Professor do Programa de Pós-Graduação em Ciências da Religião da Universidade do Estado do Pará (UEPA). josiasdacosta@gmail.com. 


\section{La mística del cuidado de Albert Schweitzer}

\section{Resumen}

El propósito de este artículo es discutir algunos aspectos de la mística del cuidado por parte de la idea de Albert Schweitzer. Su noción de "respeto a la vida" es crucial para entender su forma de pensar e implica un profundo respeto por todas las formas de vida (humanos y no humanos). Esta actitud de respeto se encuentra en su postulación ética, basada en la experiencia mística de las ganas de vivir, que se manifiesta en todos los seres vivos. Por lo tanto, es mediante la comprensión de esta noción de respeto por la vida que la mística del cuidado encuentra su expresión. El trabajo se centrará en los escritos del propio Albert Schweitzer y de Martin Heidegger para entender el concepto de cuidado.

Palavras clave: mística; cuidado; religión

\section{Primeiras considerações}

É cada vez mais crescente no Brasil, em diferentes campos do saber, estudos acadêmicos sobre mística. Esse crescimento constante não é exclusividade do Brasil e também não é algo exatamente novo, assim como não é recente o interesse que a mística desperta em intelectuais e estudiosos diversos de outras latitudes. Muitos estudos sobre mística surgiram desde o fim do século XIX e início do século XX. Em geral, esse crescimento está voltado principalmente para a mística nas grandes religiões e isso exigiu de muitos pensadores uma tomada de posição contrária ou favorável. Para lembrar aqui alguns nomes que se expressaram a respeito da mística cito: Georges Bataille (2009), Henri Bergson (2012), Martin Heidegger (2012), para ficar aqui em alguns poucos nomes.

No âmbito das ciências da religião e da teologia no Brasil também cresce cada vez mais o interesse por esse fenômeno e, com isso, surgem as dificuldades. Uma delas é quanto à definição, pois a mística pode trazer algumas implicações epistemológicas, uma vez que, para alguns estudiosos, a experiência mística é não-mediada e tem sempre um fundo comum transcendente. Com isso, é possível perceber semelhanças entre experiências místicas cristãs, islâmicas, orientais etc. Por outro lado, há aqueles que entendem as experiências místicas sempre mediadas pela cultura, pela tradição religiosa e por seus dogmas, não havendo assim um fundo comum entre as experiências. Dessa forma, enfatizam-se as diferenças entre as experiências místicas. À margem dessa discussão, é possível afirmar que na base das religiões está uma experiência do mistério, isto é, uma experiência mística. Quando homens e mulheres personalizam a experiência do mistério há o sentimento de ser habitado por ele. 
Ao dizer que a experiência mística tem como foco a vivência direta do encontro com o Sagrado, com o Mistério, com Deus, diz-se que o objetivo último dessa experiência é a união com a divindade; no cristianismo trata-se da experiência da união com Deus. Assim, a mística é uma experiência direta, imediata de Deus, ou do Uno. Ela representa o conhecimento sem a intermediação de conceitos, de modelos ou de palavras. Diante das possibilidades de discursos dissonantes, é importante tecer algumas considerações sobre a experiência mística. A forma de entender-se esse fenômeno tem muitas possibilidades e variações. Nesse sentido, é importante reconhecer que adesões ideológicas e filosóficas sempre estão implicadas nesse processo.

$\mathrm{Na}$ perspectiva de Henrique de Lima Vaz, que prioriza a mística cristã, a experiência mística é uma experiência fruitiva do Absoluto. Ele situa a experiência mística em um tríptico místico-mística-mistério:

A experiência mística, em seu teor original, situa-se justamente no interior desse triângulo: na intencionalidade experiencial que une o místico como iniciado ao Absoluto como mistério; e na linguagem com que, num segundo momento, rememorativo e reflexivo, a experiência é dita como mística e se oferece como objeto a explicações teóricas de natureza diferente (LIMA VAZ, 2000, p. 18).

Para Lima Vaz, a experiência mística foi pensada no Ocidente em três dimensões: a mística mistérica, a mística profética e a mística teórica. No caso desta última tem sua origem em Platão (LIMA VAZ, 2000, p. 35), com desdobramento no neoplatonismo (particularmente em Plotino) e na mística cristã (LIMA VAZ, 2000, p. 39). Ainda segundo Lima Vaz, a mística especulativa e a experiência metafísica têm relação e, nesse sentido, ele afirma:

...na mística especulativa a inteligência é elevada como que acima de si pelo ímpeto profundo de atingir em si mesmo o Absoluto na sua plenitude absoluta de ser. Mas como atingi-lo desta sorte sem identificar-se, de alguma maneira, com ele e sem descobrir em si mesma uma identidade original com o Absoluto? Tal é, fundamentalmente, o roteiro desenhado pela mística especulativa para seu itinerário, e que será a fonte de todos os problemas que sua prática e sua expressão teórica encontrarão ao serem recebidos pela tradição cristã (LIMA VAZ, 2000, p. 38-39).

Portanto, a mística especulativa experimentou sua queda, segundo expõe Lima Vaz, com o advento da Modernidade. A partir de René Descartes ocorre 
um processo de "secularização da mística" e ela se transforma em "filosofia especulativa”. Esse processo de "secularização" passa por Hegel, chega até Heidegger, que desenvolve em seu pensamento filosófico uma ontologia de tipo "místico-poético" (LIMA VAZ, 2000, p. 53).

Enquanto Lima Vaz privilegia sua abordagem priorizando a mística cristã, outra forma de abordar o fenômeno da mística foi esboçada pelo pensador francês George Bataille (2009). Ele prefere a expressão "experiência interior" em vez de mística. Para ele, a experiência mística não está sujeita aos princípios do mundo da racionalidade ou do sentido, caracterizando-se como uma operação soberana. Estão envolvidos movimentos que agem na razão e no sentir, e também legitima a existência do sagrado que não pode ser descrito e tocado, mas, pode sim ser experimentado na profundidade humana, como experiência interior, conforme o próprio Bataille se expressa:

Entendo por experiência interior aquilo que habitualmente chamam de experiência mística: os estados de êxtase, de arrebatamento, pelo menos de emoção meditada. Mas penso menos na experiência confessional, à qual foi preciso ater-se até agora, do que numa experiência nua, livres de amarras, mesmo de origem, a qualquer religião que seja. É por isso que não gosto da palavra mistica (BATAILLE, 2009, p. 15). ${ }^{1}$

Para Bataille, essa experiência seria esvaziada de conteúdos confessionais de expressões religiosas. Na contramão daquilo que é expresso por Lima Vaz (2000), em Bataille (2009) fica a compreensão de que nenhum ganho social e, principalmente, cognitivo há na experiência interior. Toda operação intelectual cessa, mostrando que a discursividade é uma via estreita através da qual os seres humanos se envolveram e se moveram sobre a terra. Com isso, Bataille marca a distinção entre experiência mística e filosofia, afirmando que tal diferença "reside principalmente no fato de que, na experiência, o enunciado não é nada, senão um meio, e ainda, não apenas meio, mas obstáculo; o que conta não é mais o enunciado do vento, é o vento"² (BATAILLE, 2009, p.

1 "J'entends par expérience intérieure ce que d'habitude on nome expérience mystique : les états d'extase, de ravissement, au moins d'émotion méditée. Mais je songe moins à expérience confessionelle, à laquelle on a dû se tenir jusqu'ici, qu'à une expérience nue, libre d'attaches, même d'origine, à quelque confission que ce soit. C'est pourquoi je n'aime pas le mot mystique".

$2[\ldots]$ “'reside principalement em ce que, dans l'expérience, l'ènoncé n'est rien, sinon un moyen et même, autant qu'un moyen, un obstacle; ce qui compte n'est plus l'énoncé du vent, c'est le vent". 
25). Bataille, portanto, permite afirmar que na experiência mística ocorre um esgotamento do discurso, considerando que o discurso obedece a princípios internos de organização. Mesmo sendo o discurso, que é regido por princípios organizadores da racionalidade, que orienta os seres humanos, os vazios, os silêncios, muitas vezes, gritam. Desse esgotamento do discurso brota o grito silencioso epifânico, pois a experiência interior não é discursiva.

Mesmo que as palavras drenem em nós quase toda a vida - desta vida, quase nenhum raminho que não tenha sido apreendido, arrastado, juntado pela multidão sem descanso destas formigas (as palavras). Na região das palavras, do discurso, esta parte é ignorada. Por isso, ela geralmente escapa. Só podemos em certas condições atingi-la ou dispor dela. São movimentos interiores vagos, que não dependem de nenhum objeto e não têm intenção, estados que, semelhantes a outros ligados à pureza do céu, ao perfume de um quarto, não são motivados por nada definível. Se bem que a linguagem que, a propósito dos outros, tem o céu, o quarto, ao qual se referir - e que, neste caso, dirige a atenção para o que ele apreende - fica despossuída, não pode dizer nada, limita-se a furtar desses estados a atenção (aproveitando a pouca acuidade deles, ela atrai logo a atenção alhures) (BATAILLE, 2009, p. 27). ${ }^{3}$

Mesmo que haja, afirma Bataille (2009), esse constante trabalho das formigas, que são as palavras, sempre resta na linguagem, assim é possível entender, uma poeira, um resíduo, ainda que seja, do silêncio.

A abordagem de Maria Clara Lucchetti Bingemer (2004) tem privilegiado, nos últimos anos, as experiências místicas contemporâneas. Com isso, ela tem a oportunidade de trazer à tona histórias de mulheres, como Simone Weil, Edith Stein e Etty Hillesum, que em contextos diferentes tiveram experiências com Deus. Essas experiências místicas aconteceram num contexto marcado pela violência que cada uma, a seu modo, sofreu. A abordagem de Bingemer é desde o ponto de vista de uma hermenêutica teológica, através da qual a teóloga investe na interpretação das experiências de Deus que essas três mulheres narram em seus escritos (cf. BINGEMER, 2004, p. 81). Dessa

3 "Bien que les mots drainent em nous presque tout 1 avie - de cette vie, â peu près pas une brindille que n'ait saisie, traînée, accumulée la foule sans repôs, affairée, de ces fourmis (le mots) -, il subsiste en nous une part muette, dérobée, insaisissable. Dans la région des mots, du discours, cette part est ignore. Aussi nous épochappe-t-elle d'habitude. Nous ne pouvons qu'à de certaines condition, des états qui, semblables à d'autres liés à la pureté du ciel, au parfum d'une chambre, ne sont motivés par rien de définissable, si bien que le langage qui, au sujet des autres, a le ciel, la chambre, à quoi se rapporter - et qui dirige dans c ecas l'attention (profitant de leur peu d'acuité, il atire aussitôt l'attention ailleurs". 
forma, através de um estudo comparativo da mística, Bingemer consegue apontar que a experiência mística pode ser base para a construção de uma "ética da superação da violência" rumo a uma vida pautada na busca da paz (BINGEMER, 2004, p. 82).

As abordagens das experiências místicas no mundo contemporâneo revelam também alguns aspectos que se distinguem de outras épocas. Hoje a experiência mística não tem mais as instituições religiosas como seu espaço privilegiado, uma vez que esses místicos, como revelam suas histórias de vida, estão nos espaços diversos da sociedade. Nesse sentido, houve uma ampliação dos espaços das experiências místicas, pois, ao contrário de como ocorreu até a Idade Média, hoje "os místicos, ou seja, os homens e mulheres que viveram uma experiência profunda e visceral de Deus não estão recolhidos fora do mundo ou no silêncio do claustro" (BINGEMER, 2012, p. 136). Assim, as experiências místicas no mundo contemporâneo são vividas nos espaços públicos e, por isso, os místicos enfrentam os desafios sociais e políticos do tempo em que vivem.

Este artigo se alinha a essas reflexões que buscam compreender a experiência mística no mundo contemporâneo. O título escolhido também expressa o esforço para compreender o pensamento místico de Albert Schweitzer (ano) a partir de uma de suas características. Não é tarefa simples caracterizar a mística do doutor da selva e as suas contribuições. Optei por caracterizá-la pelo cuidado, pois considero ser essa uma das mais precisas. A partir dessa perspectivação da mística de Schweitzer pretendo trazer à luz muito mais as contribuições dos seus textos para os estudos da mística do que uma discussão estéril sobre sua condição de místico.

A mística, tratada aqui como experiência de profundidade com o divino - talvez a maior das experiências humanas -, não permite que se tenha acesso direto à experiência, mas essa aproximação é permitida através das narrativas e dos textos. É nesse sentido que a postura adotada diante de Schweitzer é de atenção à contribuição dos seus textos para os estudos da mística. Portanto, a ênfase de minha reflexão não recai diretamente sobre o testemunho de sua experiência mística, mas sobre os seus textos que já derivam dessas experiências. Contudo, alguns desses testemunhos são relevantes e serão visitados.

Falar de cuidado, no contexto da atual sociedade tecnológica pautada por relações virtuais, é certamente pertinente. Essas relações no mundo virtual são ampliadas significativamente e as distâncias diminuem pelo uso da tecnologia (LÉVY, 1996, p.21), que é parte de algumas estratégias da sociedade atual para 
que a vida de afetos prevaleça (cf. MAFFESOLI, 2007, p. 50). Essa leitura trata-se, sem dúvida alguma, de uma visão mais acolhedora e menos pessimista da sociedade atual e se esforça para compreender a vida social sem ódio ou rancor e aceitando-a como ela é (MAFFESOLI, 2007, p. 213).

O outro lado da história, com uma postura mais crítica da sociedade atual, dá conta de que a sociedade da comunicação paradoxalmente ainda experimenta a solidão e a falta de comunicação entre as pessoas. Ao tempo em que o desenvolvimento tecnológico permitiu a conexão com milhões de pessoas, também possibilitou que isso seja feito sem que haja encontro físico com alguém. A exacerbação desse tipo de relação leva ao equívoco de pensar que todas as sensações podem ser mediadas pela imagem virtual, abrindo mão do toque e do contato humano.

Outra marca da sociedade atual e que tem impacto direto na vida humana e nas demais criaturas é a ainda crescente degradação do planeta. Essa crise ecológica tem alcance no âmbito da subjetividade humana, na esfera ambiental e em nível das relações sociais. Trata-se de uma crise de alcance planetário e, por isso, exige alternativas, segundo assevera Félix Guatari, em "escala planetária" (GUATARI, 1990, p. 9). Nesse sentido, se há falta de cuidado e de abandono, o descaso se objetiva na política, na dimensão espiritual, na falta de generosidade, nos rios poluídos etc.

Esse tipo de comportamento atual pode ter efeito direto no cuidado, que é a dimensão fundamental do ser humano (HEIDEGGER, 2012, p. 511). Nesse sentido, o cuidado não pode ser descartado totalmente da sociedade atual, pois é essencial. Ele pode surgir em algumas situações que se configuram como brechas da vida e, com isso, corrobora sua condição do modo de ser humano. Portanto, a dimensão do cuidado pode ser vista como crítica à sociedade atual, orientada pelo desenvolvimento tecnológico e atravessada por uma grave crise ecológica.

É, portanto, a partir da perspectiva do cuidado, como afirmei acima, que refletirei sobre a mística em Albert Schweitzer. Ele nasceu em 14 de janeiro de 1875 na pequena cidade de Kaysersberg, na Alsácia, que na época fazia parte do Império Alemão, mas atualmente trata-se de uma região da França. Era filho de um pastor luterano e neto de um prefeito de Pfaffenhofen, também na Alsácia. Curiosamente, Ludwig Schweitzer era irmão de Charles Schweitzer, o pai de Anne-Marie Schweitzer, mãe de Jean-Paul Sartre. Ou seja, Albert Schweitzer era de uma família de religiosos, de políticos e de intelectuais.

Além de pertencer a uma família com reconhecimento na vida política, acadêmica e religiosa, Schweitzer herdou também a paixão e o talento para a música. Começou a tocar piano com seu pai aos cinco anos e já aos nove anos tocava nos 
serviços religiosos da igreja na qual seu pai era pastor. Em 1893 começou sua carreira bem-sucedida como organista, em Strasbourg, e tornou-se um dos grandes intérpretes da obra de Johann Sebastian Bach. Realizou um estudo sobre a vida e a arte do compositor alemão, que resultou na obra J. S. Bach: le musicien-poète (J. S. Bach: o músico-poeta), em 1905. Trata-se de um estudo em que Schweitzer interpreta Bach como um místico religioso.

Schweitzer era também filósofo e teólogo, formado pela Universidade de Strasbourg, onde também exerceu a livre-docência na Faculdade de Teologia Protestante (1902). Ganhou fama como teólogo com a publicação de A busca do Jesus histórico, em 1906. Mais tarde, em 1923, publicou uma obra de grande abrangência intitulada Filosofia da Civilização - Primeira e Segunda Parte (SCHWEITZER, 2013), referente às conferências na Universidade de Upsala, na Suécia (1919). Mesmo tendo alcançado grande sucesso de circulação com quase cem mil exemplares, sua Filosofia da Civilização não experimentou o mesmo prestígio entre os filósofos - com exceções de Oskar Kraus, Ernst Cassirer e Karl Löwith.

Todo o sucesso profissional e artístico foi alcançado por Schweitzer antes dos trinta anos, quando abriu mão de tudo. Ele escreve que, desde os vinte e um anos, fora tomado pela certeza de que não podia aceitar a felicidade do mundo como algo natural, mas deveria pagar o seu tributo por ela. As palavras de Jesus penetravam-lhe ardentemente as entranhas: “...quem perde a sua vida por amor a mim e do Evangelho, este a possuirá." Foi então assaltado de felicidade intensa ao descobrir que sabia o que fazer: até os trinta anos faria o que lhe dava prazer, e a partir dos trinta anos daria novo rumo à sua vida, dedicando-se a cuidar do próximo. Após um período cuidando de crianças abandonadas, vagabundos e condenados, aos trinta anos de idade Schweitzer entrou para a faculdade de medicina da Universidade de Strasbourg, doutorou-se em 1913, no mesmo ano casou-se com Helèné e com ela foi para a África cuidar das pessoas pobres que eram atingidas por diversas doenças (SCHWEITZER, 1959, p. 90-94).

Ao optar seguir para África como médico, Schweitzer opta pelo silêncio, pois não falaria sobre a "religião da caridade", mas simplesmente a realizaria. $\mathrm{Na}$ África, ele viveu seu serviço como médico em três momentos: primeiro de 1913 até 1917, depois de 1924 até 1927 e finalmente de 1929 até o fim de sua vida. Suas atividades eram intensas e foram bruscamente interrompidas com a deflagração do conflito franco-alemão (04 de agosto de 1914). Como cidadãos alemães, Schweitzer e sua mulher Helène foram impedidos de clinicar durante um tempo. Nesse período ele começou a escrever sobre a decadência da cultura ocidental. 
Nos anos subsequentes ao fim dos conflitos, em 1918, Schweitzer realizou palestras na Europa, trabalhou no Hospital em Strasbourg, reassumiu suas funções de pregador na Igreja de S. Nicolau e realizou concertos de órgão pela Europa a fim de angariar fundos para o reaparelhamento do hospital em Lambarené. Ao retornar à África, como cidadão francês, contou com apoio de médicos e enfermeiros estrangeiros em seu auxílio. Foi novamente à Europa, em 1927, para uma temporada de concertos objetivando angariar mais recursos financeiros. Dois anos depois retornou definitivamente à África.

O hospital de Lambarené ${ }^{4}$ tornou-se referência no tratamento de doenças tropicais e atraiu muitos cientistas e médicos, que se revezavam com Schweitzer no atendimento. $\mathrm{O}$ alcance e a natureza humanitária do projeto conferiram a Albert Schweitzer o prêmio Nobel da Paz de 1952. A utilização de energia atômica com fins militares também impactou e motivou Schweitzer a realizar conferências que alertavam sobre os perigos da corrida armamentista e a ameaça concreta da possibilidade de uma nova guerra muito mais devastadora que colocaria em risco a existência humana (SCHWEITZER, 1959, p. 117-162). No dia 04 de setembro de 1965, aos noventa e cinco anos, Albert Schweitzer morreu em Lambarené exercendo plenamente suas atividades.

\section{A noção de reverência pela vida e a mística do cuidado}

Para Albert Schweitzer, os projetos filosóficos e éticos deixaram muitas lacunas e não conseguiram tocar naquilo que devia ser o principal, por isso ele está disposto a preencher esses espaços. Como pensador, ele está muito associado ao seu projeto que ganha forma através de uma filosofia da civilização, que passa em revista, de modo sintético e objetivo, mas sem prejuízo para a análise crítica, as várias concepções do mundo: filosófica, religiosa, ética; utilitarista, pessimista, otimista (SCHWEITZER, 1959, p. 75-83).

Schweitzer se empenha fortemente para deixar claro que o problema ético está centralizado na busca de um princípio básico da moral, e essa era a grande e a principal carência, percebida e denunciada por ele, das concepções éticas anteriores. Segundo ele, tais concepções éticas continham apenas fragmentos do princípio básico da moral, mas não conseguiram penetrá-lo de fato. Na perspectiva de Schweitzer, pareciam estar com os olhos vendados e assim foram impedidos e não puderam perceber o ponto principal, que é o princípio básico da moral.

4 Sobre o Hospital e a Fundação Albert Schweitzer ver: http://www.schweitzerlambarene. org $/ \mathrm{fr} /$. 
O grande interesse vitalista foi o que motivou Schweitzer a ler os pensadores dessas diferentes épocas. Dessa forma, interessaram-lhe estritamente "os argumentos por meio dos quais eles fundaram a Ética" (SCHWEITZER, 2013, p. 95). ${ }^{5}$ Isso expressa, de algum modo, uma busca intensa, longa, e até mesmo angustiante, uma verdadeira peregrinação movida por algo que o toma visceralmente, mas que alcança seu objetivo. Sua busca dura algum tempo, até que em uma longa viagem navegando pelas águas do rio Ogooué, na primavera de 1915, Schweitzer relata a seguinte experiência:

...devagarinho subimos o rio, tateando penosamente por entre bancos de areia, pois era época de sêca. Perdido em pensamentos, ficava sentado no convés da chata, empenhado na luta pelo conceito elementar e universal do ético que eu jamais encontrara em filosofia alguma. Enchia folhas e mais folhas com frases desconexas, unicamente para permanecer concentrado no problema. $\mathrm{Na}$ noite do terceiro dia, quando, ao pôr do sol, navegávamos por entre rebanho de hipopótamos, subitamente me ocorreu aquilo que eu não havia suspeitado nem procurado: a 'reverência pela vida'. A porta de ferro cedera e abrira-se um caminho através da confusão. Eis que, finalmente, penetrara até a ideia na qual estão contidas juntamente a afirmação do mundo e da vida, e a ética! Agora sabia que a concepção do mundo, afirmadora do mundo e da vida, juntamente com seus ideais de cultura, se baseiam no raciocínio (SCHWEITZER, 1959, p. 163).

A narrativa de Schweitzer é descrita nos moldes de uma experiência religiosa mística, ${ }^{6}$ na medida em que se trata de uma experiência central e fundante em sua vida. Seu relato é perpassado de simbolismo (“...na noite do terceiro dia...”) e sua busca era pelo conceito fundamental da ética - não encontrado por ele na tradição filosófica. Ao buscar esse princípio que nele estava encarnado, ele encontrou o que não procurava, mas que surgiu em seu pensamento, subitamente, como um raio que o atingira em forma de frase: reverência pela vida. Isso o surpreendeu, mas também deixou a certeza de onde está situado esse princípio: no pensamento. Mais adiante, ao explicar o que é e como nasce a reverência pela vida, Schweitzer o faz nos seguintes termos:

5 Schweitzer critica a obra mais importante sobre a história da ética naquele momento, escrita por Friedrich Jodl: "Geschichte der Ethik als philosophische Wissenschaft" (História da ética como ciência filosófica), pois seu autor não mediu a distância que as diferentes concepções resguardavam do princípio básico da moral.

6 Aqui acompanho Bernard McGuinn, quando afirma: "Albert Schweitzer falou com reservas sobre pelo menos uma experiência central em sua vida que poderia ser descrita como mística” (MCGUINN, 2012, p. 389). 
...se o homem quer chegar à clareza sobre si mesmo e sua relação com o mundo, tem que abstrair sempre de novo dos numerosos pormenores que constituem seus pensamentos e seu saber, e lembrar-se do fato básico, imediato e sempre presente, que é a sua consciência. Só partindo dela poderá chegar a uma concepção do mundo pensante (SCHWEITZER, 1959, p. 164).

Continua a estrutura narrativa, aos moldes da mística, em que se dá a explicação. Schweitzer concebe a possibilidade de conhecimento imediato através da razão, veículo através do qual se pode alcançar e conceber o mundo. Ele critica o axioma cogito ergo sum, de Descartes, pois este envereda pela abstração; é oco, sem que pudesse conduzir o ser humano a uma relação consigo mesmo e com o mundo, antes colocando no caminho do pensamento moderno uma nebulosa abstrata e, ao mesmo tempo, cerrando as portas que levariam à ética. Assim, para Schweitzer, o ato de pensar deve necessariamente conduzir a algo, pois pensar possui um conteúdo: 'eu sou vida que quer viver, no meio da vida que quer viver' (SCHWEITZER, 2013, p. 285). Nessa tautologia, ele afirma que esse deve ser o postulado da filosofia, como também deve ser o da religião, através de suas diferentes expressões. Nesse sentido, racional é aquele que pensa sobre si e sobre a vida, que não se limita ao humano, mas se estende às criaturas não humanas. Por isso, ele insiste em dizer que "a afirmação da vida é aprofundamento, é espiritualização e é um crescente impulso da vontade de viver” (SCHWEITZER, 1959, p. 165). Ou seja, o ser humano racional é aquele que afirma a vida, toda forma de vida.

A mística aqui está ligada a uma experiência abrangente através da qual é capaz de captar a totalidade das coisas como totalidade orgânica, plena de valor e de significação. Schweitzer (1959) enfaticamente assume uma postura crítica frente à limitação do projeto filosófico moderno, que contribuiu para pensar a vida fundamentada sobre os ideais técnico-científicos da sociedade moderna. Todavia, Schweitzer propõe uma análise mais aprofundada nos seus valores éticos e espirituais, encontrados no sentimento de respeito pela vida, que se fundamentam em si mesmo e nela se encontra uma visão ética do mundo. Segundo critica Schweitzer, isso não se dá por meio de um ato cognoscitivo, mas através de experiência imediata do mundo. Nesse sentido, quando o pensamento se lança em profundidade acaba no misticismo ético.

Como protestante europeu criado no círculo da tradição do liberalismo teológico, que privilegia a moral evangélica em detrimento dos dogmas, não é de se criar espanto que o pensamento e a vida de Schweitzer tenham esse núcleo do misticismo ético. Portanto, mística e ética se encontram e Schweitzer destaca, 
a partir de Paulo, a supremacia do ético na religião, demonstrada na concretude do cuidado ao outro, assim como foi sua vida na selva africana (SCHWEITZER, 1959, p. 388-389). Com isso, como místico, ele pode ser qualificado sob a alcunha de místico do cuidado.

Seu trabalho filosófico mostra ainda que da afirmação da vida e do mundo emerge a mística ética baseada no pensamento fundamental, que é a preocupação com necessidades primárias da vida. Essa mística ética resulta de herança religiosa, da vontade e também de uma visão científica do mundo, que se apresenta na sua filosofia da reverência pela vida. Conforme afirma:

...se de alguma maneira minha vida dedicar-se à vida, meu desejo de viver finito experimenta a unificação com o desejo de viver infinito, no qual toda a vida é apenas uma. Recebo o refresco que me protege do calor sufocante no deserto da vida (...) A intuição e o anseio de toda a religiosidade profunda estão contidos na ética do respeito à vida (SCHWEITZER, 1959, p. 288).

Schweitzer rejeita expressões religiosas, místicas ou pensamento filosófico que negam o mundo e a vontade de viver em benefício de uma inegociável afirmação da vida e do mundo. Nesse processo de intensificação da vida e do mundo, tanto a dimensão científica, a vontade, como também a religiosidade, são assumidas na ética do respeito à vida.

Nessa perspectiva vitalista, pensar a religião significa pensar a religião que celebra e afirma a vida, pois não há espaço para que a religião não demonstre clareza em querer este mundo e a vida que nele pulsa. Não há espaço para a celebração da destruição da vida em todas as suas dimensões, pois a partir da noção reverência pela vida, Schweitzer busca a religião da incondicional afirmação da vida e do mundo. A afirmação incondicional significa não estabelecer critérios qualitativos a partir da saúde e da perfeição, mas isso necessariamente deve incluir a vida fragilizada, debilitada, deficiente. Nesse universo, o que é mais importante é afirmar a vida, a vida de todas as criaturas, de todo ser humano e a sua própria vida. Essa é a base a partir da qual também se pode compreender a mística do cuidado em Schweitzer.

\section{A mística do cuidado}

Como afirmei acima, o cuidado é a dimensão fundamental do ser humano, isto é, a sua essência é o cuidado. Nesse sentido, Leonardo Boff vai afirmar que o cuidado é a base a partir da qual podem ser identificados os princípios e valores que vão orientar as ações justas e retas do ser humano. Além disso, o cuidado, 
que se opõe ao descuido e não se encerra em atos pontuais, representa uma atitude de preocupação e de responsabilidade com o outro. Ou seja, o cuidado implica "envolvimento afetivo com o outro" (BOFF, 1999, p. 33). Tentarei aqui compreender a noção de cuidado a partir de Martin Heidegger, que dedicou todo o sexto capítulo da obra Ser e tempo ao cuidado, isto é, parágrafos 39-44.

$\mathrm{Na}$ perspectiva histórico-linguística, o cuidado não tem sentido unívoco e aponta para múltiplas possibilidades compreensivas. Alguns vão derivar a palavra cuidado do latim cura. Esse foi o caso de Martin Heidegger, ao adotar o sinônimo erudito de cuidado em sua obra Ser e tempo (HEIDEGGER, 2012). O sentido clássico apontava para relações amorosas e de amizades e expressava atitude de cuidado com a pessoa amada ou por algo estimado. A palavra cura ganhou novas derivações até chegar à forma que hoje é conhecida como cuidado. É possível insistir que o sentido de cura permaneceu como atitude de interesse e de preocupação com o outro.

O cuidado tem abrangência maior quando se pensa como dimensão originária, antes de toda a situação, algo constitutivo do ser humano. Um fenômeno base que possibilita a própria existência humana enquanto humana. Nas palavras de Heidegger: "o cuidado, como totalidade-estrutural-originária, reside existenciariamente a priori 'antes', isto é, já sempre em cada 'comportamento' factual e ‘situação' do Dasein’” (HEIDEGGER, 2012, p. 541). Trata-se de um fenômeno ontológico-existencial fundamental. Com isso, o ser humano é revelado em sentido mais amplo e profundo a partir do cuidado. Portanto, em uma cultura marcada pelo avanço da tecnologia, como a atual, e, ao mesmo tempo, pela falta de cuidado, o ser humano, de modo mais amplo e integral, fica obscurecido.

Essa dimensão do cuidado também, conforme postulado por Heidegger, não se encerra no âmbito da individualidade. Isso porque a designação do cuidado não aponta para um isolamento comportamental, mas, o preocupar-se consigo mesmo traz, com ele, a estrutura que contempla o outro. Portanto, o cuidado nunca pode ser tomado a partir de uma compreensão exclusivamente particular, pois "o cuidado é sempre, embora só privativamente, ocupação e preocupação-com -o-outro" (HEIDEGGER, 2012, p. 543) Nesse sentido, o cuidado é constitutivo do modo de ser humano, isto é, o que caracteriza o ser humano como humano, mas não somente isso, pois esse ser humano também é considerado como tal na sua relação com o outro.

Do modo como o cuidado é pensado por Heidegger, pode-se dizer que o ser humano se estrutura e se plenifica somente através do cuidado. Isso significa que sem cuidado não há ser humano. Sem cuidado - tanto para doar quanto para 
receber - o ser humano perde o sentido, morre. Sem cuidado, o mal, o prejuízo ao outro e a si mesmo tornam-se praticamente inevitáveis. Nessa perspectiva, abre-se a possibilidade de questionar sobre o que é o ser humano. A resposta vai variar de acordo com os instrumentais utilizados para a análise, a sua época e a corrente filosófica. Se a pergunta estiver perspectivada pela sociedade tecnológica, a resposta deve passar pela marca de suas relações virtuais. Se a perspectiva for de uma sociedade marcada pela dominação da natureza, a resposta ganha sentido se for pensada pelo viés da compreensão de superioridade humana em relação aos demais seres vivos.

Por outro lado, se a vida humana for perspectivada pelos grandes místicos, segundo Henri Bergson, o ser humano é aquele que, a partir da capacidade de diálogo com o mistério ou do alinhamento da vontade humana com a vontade divina, age para a transformação do mundo (BERGSON, 2012, p. 300). Nesse sentido, o ser humano é o ser em relação ao outro, sempre se relacionando com o outro, isto é, o ser humano é um ser de cuidado. O cuidado, portanto, é a marca que caracteriza, que singulariza, que distingue o ser humano.

Em Albert Schweitzer, o jeito-de-ser-cuidado está sempre muito presente em sua biografia e em seu trabalho intelectual. Esse cuidado se manifesta de tal modo que o impulsiona em atitude de envolvimento em direção ao outro. Não somente ao ser humano, mas, a todas as criaturas vivas, a todos os seres (humanos e não humanos). Por isso, afirma: "o homem só é ético quando a vida como tal, quer da planta quer do animal e do homem, lhe é sagrada, e quando sai em socorro da vida periclitante" (SCHWEITZER, 1959, p. 165-166). Tal concepção permite pensar que essa postura se configura como obrigação de ver a todos os seres vivos, com seus respectivos desejos de vida e potencialidades, com o mesmo respeito que se tem ao próprio desejo de viver, de continuar vivo.

Essa concepção, que arremessa Schweitzer sem freio em direção ao outro, também tem influxo em seu misticismo, que nada tem de abstrato, muito pelo contrário. Sua rejeição ao abstrato se mostra na defesa que faz de um misticismo que não se encerra no êxtase, mas se desdobra em ação na direção do outro. Segundo ele, "a realidade desconhece a maneira como o indivíduo poderá estabelecer uma relação com a totalidade do ser" (SCHWEITZER, 1959, p. 281). O que a realidade conhece, conforme Schweitzer, é a manifestação do ser em cada indivíduo e, por isso, a identificação não é imediata com o ser, mas se dá por meio das relações entre os indivíduos. O misticismo real é aquele que rejeita as abstrações e se converte em ação. ${ }^{7}$ Portanto, a identidade com o ser se objetiva na medida em que há dedicação ao outro.

Essa ideia se alinha perfeitamente ao que Bergson chamou de misticismo completo, isto é, aquele que não parou no êxtase, mas avançou para ações concretas em favor da humanidade (ver BERGSON, 2012, p. 187). 
O místico é dotado de uma força tal que o lança às mais diversas iniciativas, pois a sua alma está repleta de generosidade e do desejo de compartilhar com a humanidade o amor em cuja fonte ele bebeu. Além disso, os místicos superam suas limitações humanas, pois possuem uma grande evolução interior, onde suas ações demonstram comprometimento e amor pela humanidade (BERGSON, 2012, p. 303). Nesse sentido, o objetivo dos místicos é transformar a humanidade (BERGSON, 2012, 310). O que salta da vida e da obra de Schweitzer é esse objetivo, isto é, o de lançar-se em direção ao outro a fim de impactar e transformar positivamente as pessoas e o mundo, movido pelo amor que ele experimentou. Ou seja, sua ação não se caracteriza por uma motivação de interesse individual, antes é marcada pelo desinteresse de si em benefício do outro. Portanto, trata-se de uma atitude que tem a capacidade de levar a solidariedade para além dos limites do natural.

Essa postura acima mencionada de Schweitzer também resulta de sua compreensão de mística. Para ele, há basicamente dois misticismos: o primitivo e o desenvolvido. O primeiro, segundo ele, não progrediu para uma concepção universal, estando ainda limitado a conceitos básicos sobre o terreno e o extraterreno, sobre o que é temporal e eterno. Nessa compreensão, entrar no extraterreno e no eterno se dá através do mistério ou de um ato mágico. A identidade com o divino pode acontecer através de ingestão de alimentos e ou bebidas ritualísticas.

$\mathrm{Na}$ forma mais desenvolvida, o ser humano tem uma concepção sobre o universal e ele é capaz de refletir sobre sua "relação com a totalidade do ser e com o Ser em si mesmo", resultando num misticismo mais ampliado e aprofundado. Nesse misticismo, o contato com o extraterreno e com o terreno se dá através do pensamento, quando "a personalidade consciente ergue-se acima daquela ilusão dos sentidos que o faz considerar-se na vida presente como em cativeiro ao terreno e temporal" (SCHWEITZER, 2006, p. 22). Nesse sentido, o ser humano, ao reconhecer a unidade de todas as coisas em Deus, no Ser, tem consciência de si mesmo com Deus, “em cada momento eterno" (SCHWEITZER, 2006, p. 22). Esse misticismo intelectual adquire existência quando o pensamento se esforça para conceber a relação da personalidade com o universal. Esse mesmo misticismo se apresenta em diversas expressões, correntes de pensamentos e pensadores. Isso faz com que ele seja diferente, dependendo, assim, do tempo e do lugar em que são vividos (SCHWEITZER, 2006, p. 22-23).

Para o doutor das selvas, o misticismo cristão está entre o primitivo e o intelectual, pois, a partir de Paulo, ele percebe que este não fala de um estar com Deus ou de ser um com ele, como uma relação mística imediata com Deus, mas, Paulo se remete sempre para uma relação com Deus realizada por meio da união 
mística com Cristo. No estar-em-Cristo é que se pode "conhecer a si mesmo como um ser que é elevado acima deste mundo sensorial" (SCHWEITZER, 2006, p. 24). Esse estar-em-Cristo é o ponto a partir do qual emerge o jeito-de-ser-cuidado que Schweitzer encarnou e seguiu. Para ele, a singularidade da mística centrada no Cristo, que conjuga a mística primitiva com a intelectual, é o que lhe confere, conforme Bernard McGinn, o status de "a única mística cristã verdadeira" (MCGUINN, 2012, p. 391). Portanto, o modo como ele a viveu não o limitou ao êxtase e à contemplação, pois a marca que Schweitzer trazia inscrita em si era a da generosidade e do desejo de partilhar o amor que ele conhecia.

\section{O cuidado para com tudo e com todos}

O que importa é afirmar a vida incondicionalmente e isso significa afirmar toda e qualquer forma de vida, sem que haja o julgamento prévio sobre o merecimento de simpatia ou de valor. Não cabe o questionamento sobre qual é a vida que deve ou não continuar, qual é a mais ou menos valiosa, quem é capaz ou não de sentir. O ser ético, enfatiza Schweitzer, é aquele que está aberto à imperiosa vontade de oferecer ajuda a todo e qualquer ser vivo, pois, segundo afirma, "para ele, sagrada é a vida como tal" (SCHWEITZER, 2013, p. 286).

A dimensão de cuidado se estende para além do ser humano e é movida pela certeza de que tudo é perpassado pelo divino. Isso confere a Schweitzer a convicção de que todo e qualquer esforço para manter viva todas as formas de vida é necessário e vale a pena, pois esse é o verdadeiro comportamento do ser humano ético. Essa certeza é também acompanhada da consciência de que Schweitzer está um passo à frente do seu tempo, conforme afirma:

...hoje acreditamos ser exagero dispensar atenção contínua a toda criatura viva, até suas manifestações mais ínfimas... Entretanto chegará o momento no qual nos surpreenderemos pelo fato de que a humanidade precisou de tanto tempo para enxergar o dano irrefletido à vida como algo incompatível com a ética (SCHWEITZER, 2013, p. 286).

A capacidade de antecipar preocupações que até então não faziam parte da agenda de sua época não é por acaso, pois os místicos são dotados de uma grande sensibilidade e de grande capacidade intelectual. ${ }^{8}$ Não deve haver, por-

\footnotetext{
8 André Mary afirma que o "misticismo é a dilatação da inteligência adquirida por uma vontade de ferro e um firme esforço moral de aniquilação do eu" (MARY, 2015, p. 138). Em perspectiva semelhante, Henry Bergson chega a qualificar o místico como gênio, por alcançar algo "inacessível”, e isso, ele afirma, "não é por acidente, é em virtude de sua própria essência” (BERGSON, 2012, p. 285).
} 
tanto, limites na preocupação e responsabilidade para com tudo que vive, pois para Schweitzer, tudo é dotado de sacralidade. Nesse sentido, emerge a atitude de preocupação e cuidado para com tudo que vive. É nesse fomento e nesse processo de intensificação da vida que se aloca a religião: "a intuição e o anseio de toda a religiosidade profunda estão contidos na ética do respeito à vida” (SCHWEITZER, 2013, p. 288).

A postura radical de defesa da vida é a única possibilidade, para Schweitzer, que não negocia com o comportamento humano pautado por uma ética relativa. Sua postulação é pela inegociável defesa da vida, que resulta em críticas severas a todas as formas de prejuízo à vida (humana e não humana). O limite do "inevitável" e do "necessário" não deve ser ultrapassado, ou seja, os prejuízos causados às demais criaturas devem ser somente os inevitáveis, assim como o uso dos recursos naturais devem ser somente para o que for necessário. Trata-se, portanto, de defender uma relação de profunda reverência a tudo que é vivo, a ponto de indignar-se com o sofrimento de animais usados como cobaias ou que sofrem outros tipos de maus tratos, conforme Schweitzer denuncia: "quanta tortura sofrem os animais apenas para demonstrar aos alunos fenômenos conhecidos!" (SCHWEITZER, 2013, p. 293). Portanto, sua defesa é por atos responsáveis para com tudo e todos que estão vivos.

Fica evidenciada em Schweitzer, a rejeição de uma concepção de ser humano que se coloca no centro da natureza que deve estar ao seu inteiro dispor a fim de lhe servir sem medida. Por isso, ele defende com ardor e de modo incansável uma postura de vida que é a da absoluta e inegociável vontade de viver, que reverencia e afirma incondicionalmente não apenas alguns modos de viver ou algumas formas de vida, como se houvesse o privilégio de um sobre outro. Todavia, os processos de intensificação da vida, segundo postula Schweitzer, valem para todo desejo de viver e todas as formas de vida.

Para Schweitzer, todo conhecimento se metamorfoseia em experiência vivida e, com isso, o conhecimento do mundo converte-se em experiência do mundo. Dessa forma, não se admite nenhuma atitude do ser humano com o mundo que não seja de estreita relação e cuidado com ele, conforme afirma: "preenche meu íntimo com veneração pelo misterioso desejo de viver que existe em tudo" (SCHWEITZER, 2013, p. 284). Portanto, a relação entre o ser humano e o mundo é possível na medida em que o seu desejo de viver experimenta juntamente com outro desejo de viver tudo aquilo que o rodeia. 


\section{Apontamentos finais}

A mística do cuidado de Albert Schweitzer apresenta-se como uma canção de celebração da vida. Sua vida e obra têm a seta apontada para a afirmação de todas as formas de vida e da vida toda. A partir de uma experiência religiosa profunda, com base fortemente protestante, centrada na figura de Cristo, Schweitzer abre mão de todos os privilégios que uma vida de sucesso profissional, artístico e intelectual poderia oferecer, para entregar-se radicalmente a uma vida de cuidado ao outro, cuja potência de agir não é marcada pelo interesse pessoal, mas, pelo desinteresse de si em benefício do outro, caracterizando a abertura como critério de seu misticismo.

A dimensão do cuidado como dimensão originária do ser humano, que é a base a partir da qual possibilita a própria existência humana enquanto humana, transborda dos textos de Schweitzer e revela o quanto ele encarna esse ser que se abre em cuidado de si e do outro. A mística tomada a partir da dimensão do cuidado oportuniza a reflexão crítica da sociedade atual, marcada pela exacerbação das relações virtuais, pela ilusão de que tudo pode ser reproduzido e vivido na dimensão virtual, caracterizando, assim, a ilusão do estreitamento das relações e dos afetos. Ao mesmo tempo, esse "outro", em Schweitzer, é ampliado para além do humano e, com isso também, abre-se a oportunidade para a reflexão necessária do cuidado para com o planeta.

Finalmente, a atitude de respeito e profunda reverência pela vida caracterizamse, consequentemente, em atos concretos de respeito a todas as formas de vida. Essa atitude está na postulação ética de Schweitzer, fundamentada na experiência mística da vontade de viver que se manifesta em todos os seres vivos. Em uma sociedade que de modo geral ainda é marcada pela falta de cuidado com o nosso planeta, a mística inspira atitudes de cuidado pelo outro, que se estende ao meio em que vivemos. Portanto, a mística a partir de Schweitzer postula experiência de cuidado por tudo que está vivo, através da entrega, do serviço ao outro, a fim de assisti-lo em suas necessidades, pois a mística do cuidado é a afirmação da vida na sua plenitude.

\section{Referências}

BATAILLE, Georges. L'expérience intérieure. Paris: Gallimard, 2009.

BERGSON, Henri. Les Deux Sources de la morale et la religion. Paris : Édition Flammarion, 2012.

BINGEMER, Maria Clara Lucchetti. Gênero, mística e violência (três mulheres judias diante de Deus e da violência do Holocausto). In: TEIXEIRA, Faustino. (Org.). No limiar do mistério. Mística e religião. São Paulo: Paulinas, 2004. 
BINGEMER, Maria Clara Lucchetti. Simone Weil : uma mística para o século XXI. In: TEIXEIRA, Faustino. (Org.). Caminhos da mística. São Paulo: Paulinas, 2012.

BOFF, Leonardo. Saber cuidar: ética do humano - compaixão pela terra. Petrópolis: Vozes, 1999. GUATARI, Félix. As três ecologias. Campinas: Papirus, 1990.

HEIDEGGER, Martin. Ser e tempo. Petrópolis: Vozes, 2012.

LÉVY, Pierre. O que é o virtual ? São Paulo: Editora 34, 1996.

LIMA VAZ, Henrique C. Experiência mística e filosofia na tradição ocidental. São Paulo: Edições Loyola, 2000.

MAFFESOLI, Michel. O ritmo da vida: variações sobre o imaginário pós-moderno. Rio de Janeiro: Record, 2007.

MARY, André. Os antropólogos e a religião. São Paulo: Ideias \& Letras, 2015.

MCGINN, Bernard. As fundações da mística: das origens ao século V. São Paulo: Paulus, 2012. SCHWEITZER, Albert. A busca do Jesus histórico. São Paulo: Fonte Editorial, 2003.

SCHWEITZER, Albert. Cultura e ética. São Paulo: Edições Melhoramentos, 1953.

SCHWEITZER, Albert. Filosofia da civilização: queda e reconstrução da civilização e ética. São Paulo: UNESP, 2013.

SCHWEITZER, Albert. J. S. Bach: le musicien-poète. Paris : Costallat, 1904.

SCHWEITZER, Albert. Minha vida e minhas ideias. São Paulo: Edições Melhoramentos, 1959.

SCHWEITZER, Albert. O misticismo de Paulo, o apóstolo. São Paulo: Fonte Editorial, 2006.

Submetido em: 15-5-2016

Aceito em: 7-4-2017 